\title{
Effect of Bacillus clausii Capsules in Reducing Adverse Effects Associated with Helicobacter pylori Eradication Therapy: A Randomized, Double-Blind, Controlled Trial
}

Manuel Plomer · Marcos III Perez · Dorothea Maren Greifenberg

Received: July 16, 2020 / Published online: September 8, 2020

(C) The Author(s) 2020, Corrected publication 2020

\section{ABSTRACT}

Introduction: Antibiotic treatment can alter the gut microbiome and cause short-term gastrointestinal adverse effects (AEs). This study assessed the efficacy of lyophilized capsules containing $2 \times 10^{9}$ spores of Bacillus clausii (Enterogermina ${ }^{\circledR}$; Sanofi Synthelabo) in reducing AEs associated with Helicobacter pylori eradication therapy in Italy.

Methods: In this randomized, double-blind, single-center, phase IIIB study, 130 adult outpatients with $H$. pylori infection were assigned to receive one Enterogermina ${ }^{\circledR}$ capsule or placebo three times daily for 2 weeks (1:1). During week 1, all patients received clarithromycin $500 \mathrm{mg}$, amoxicillin $1 \mathrm{~g}$, and rabeprazole $20 \mathrm{mg}$ twice daily. The primary efficacy outcome was the presence of diarrhea in week 1 .

Digital Features To view digital features for this article go to https://doi.org/10.6084/m9.figshare.12841409.

M. Plomer · M. III Perez · D. M. Greifenberg ( $\square)$ Consumer Healthcare, Sanofi-Aventis Deutschland GmbH, Industriepark Höchst, Frankfurt am Main, Germany

e-mail: Dorothea.Greifenberg@sanofi.com
Results: A total of 130 patients were randomized. The incidence of diarrhea in week 1 was $29 \%$ in the B. clausii group and $48 \%$ in the placebo group [relative risk (RR) $0.61 ; 95 \%$ confidence interval (CI) $0.39-0.97 ; p=0.03$ ]. The incidence of diarrhea remained lower with $B$. clausii than with placebo in week 2 (RR 0.38 ; 95\% CI $0.14-1.02 ; p=0.0422$ ). In week 1 , the number of days without diarrhea was significantly higher in the $B$. clausii group than in the placebo group (6.25 vs. $5.86 ; p=0.0304)$. In both groups, the number of days without diarrhea increased significantly $(p<0.0001)$ from week 1 to week 2 . A total of three AEs occurred in two patients in the placebo group, but none were serious.

Conclusions: Compared with placebo, Enterogermina $^{\circledR}$ reduced the incidence of, and the number of days with, diarrhea in patients receiving $H$. pylori eradication therapy. Enterogermina ${ }^{\circledR}$ was well tolerated.

Keywords: Bacillus clausii; Clinical trial; Diarrhea; Enterogermina; Eradication therapy; Helicobacter pylori; Probiotics 


\section{Key Summary Points}

\section{Why carry out this study?}

Recommended antibiotic treatments for Heliobacter pylori eradication cause shortterm gastrointestinal adverse effects (AEs), such as diarrhea, nausea, vomiting, bloating, and abdominal pain. Such AEs can result in treatment discontinuation, and may increase the risk of treatment failure and/or developing antibiotic resistance.

This study aimed to assess and confirm the efficacy of a spore-based probiotic containing spores of four antibioticresistant $B$. clausii strains

$\left(\right.$ Enterogermina $\left.^{\circledR}\right)$ in reducing and preventing the AEs associated with $H$. pylori eradication therapy using the galenic form of capsules.

\section{What was learned from the study?}

Compared with placebo, Enterogermina ${ }^{\circledR}$ reduced the incidence of, and the number of days with, diarrhea in patients receiving $H$. pylori eradication therapy.

Probiotic supplementation with B. clausii capsule formulation during 7-day tripletherapy for $H$. pylori eradication was well tolerated and effective in reducing the incidence of, and the number of days with, diarrhea.

\section{DIGITAL FEATURES}

This article is published with digital features to facilitate understanding of the article. You can access the digital features on the article's associated Figshare page. To view digital features for this article go to https://doi.org/10.6084/m9. figshare.12841409.

\section{INTRODUCTION}

The recommended treatment for Helicobacter pylori eradication in regions of the world with clarithromycin resistance $<15 \%$ is protonpump inhibitor (PPI)-clarithromycin-containing triple therapy, while in areas with high (>15\%) clarithromycin resistance, the recommended therapy is bismuth quadruple or nonbismuth quadruple therapies [1, 2]. However, antibiotic treatment can alter the gut microbiome and cause short-term gastrointestinal adverse effects (AEs), such as diarrhea, nausea, vomiting, bloating, and abdominal pain $[1,3]$. These AEs can result in treatment discontinuation [2], which, in turn, may increase the risk of treatment failure and/or developing antibiotic resistance $[1,2,4,5]$.

Probiotics are "live microorganisms which when administered in adequate amounts confer a health benefit on the host" [6, 7]. Probiotics mediate their effects via several mechanisms, including colonization and normalization of perturbed intestinal microbiota, competitive exclusion of pathogens, and modulation of the immune system [8-11]. In addition to improving eradication rates and reducing the development of antibiotic-associated diarrhea $[12$, 13], certain probiotics, such as Saccharomyces boulardii and Bacillus clausii, may reduce gastrointestinal AEs associated with $H$. pylori eradication therapies [1,5].

Bacillus species are ubiquitous in the environment, and found in soil, water, plants, mammals, aquatic animals, insects, and other invertebrates [14]. They are Gram-positive, rodshaped bacteria with the ability to produce a robust spore to survive environmental stress and harsh conditions, such as extreme $\mathrm{pH}$ (e.g., bile fluids), temperatures, and dry conditions [14]. B. clausii has been used widely in Italy since the 1960s for antibiotic-related AEs [15]. $B$. clausii spores can survive transit through the gut, where they germinate, grow, and multiply as vegetative cells. Enterogermina ${ }^{\circledR}$ (Sanofi Synthelabo) is a spore-based probiotic containing spores of four antibiotic-resistant $B$. clausii strains $(O / C, N / R, S I N, T)$ [16]. It is available in 55 countries around the world in several 
formulations: liquid vials or lyophilized capsules containing 2 billion colony-forming units (CFU), liquid vials containing 4 billion CFU, and lyophilized powder for suspension and orodispersible granules containing 6 billion CFU [17]. Lyophilized capsules and liquid vials containing 2 billion CFU were bioequivalent, with $B$. clausii found alive in feces for up to 12 days after administration [16]. A previous study demonstrated the efficacy of Enterogermina ${ }^{\circledR} 2$ billion vial formulation of $B$. clausii versus placebo in reducing gastrointestinal symptoms (nausea, diarrhea, epigastric pain, and taste disturbance) associated with $H$. pylori eradication using 7-day PPI and antibiotic-based therapy [15].

This study aimed to assess the efficacy of Enterogermina $^{\circledR} 2$ billion capsule formulation of $B$. clausii in reducing and preventing the AEs associated with $H$. pylori eradication therapy.

\section{METHODS}

\section{Study Design and Patients}

This randomized, double-blind, single-center, placebo-controlled, parallel-group, phase $3 \mathrm{~b}$ study was conducted at the Gastroenterology and Internal Medicine Day Hospital, Gemelli Hospital, Rome, Italy.

Between June 2003 and April 2004, 130 consecutive male or female outpatients who had gastric $H$. pylori infection (as confirmed by a ${ }^{13} \mathrm{C}$-urea breath test) were enrolled. Patients were aged 18-65 years and did not have gastrointestinal symptoms in the 3 months prior to enrolment. Exclusion criteria included any concomitant therapy within 3 months of the study, use of laxatives, antidiarrheal agents or probiotics within 3 months of the study, and acute or chronic gastrointestinal diseases, diabetes, or chronic debilitating diseases.

All patients were required to sign a written informed consent form before participating in the clinical trial. The institution's Independent Ethics Committee (Comitato Etico, Università Cattolica del Sacro Cuore, Policlinico A. Gemelli, Largo Gemelli, 8, 00,168 Roma) approved the study protocol in April 2003, and the study was performed according to the Helsinki declaration and in compliance with the International Council for Harmonisation of Technical Requirements for Registration of Pharmaceuticals for Human Use Good Clinical Practice guidelines adopted by the European Medicines Agency. The trial was conducted between June 2003 and May 2004, before the European database for clinical trials (EudraCT) was established, and is therefore not registered in a clinical study database.

\section{Treatments}

Patients were randomly assigned (1:1) to receive one Enterogermina ${ }^{\circledR}$ capsule (containing $2 \times 10^{9}$ spores of polyantibiotic-resistant $B$. clausii) three times daily (for a total of $6 \times 10^{9} \mathrm{CFU}$ per day) or matching placebo capsule three times daily, for 2 weeks. Randomization was conducted using SAS software. During week 1 of treatment, all patients received triple therapy with clarithromycin $500 \mathrm{mg}$ twice daily, amoxicillin $1 \mathrm{~g}$ twice daily, and rabeprazole $20 \mathrm{mg}$ twice daily for $H$. pylori eradication. After 2 weeks of treatment, patients were followed-up for another 2 weeks.

\section{Efficacy and Safety Assessments}

Patients were assessed at baseline (visit 0) and at weeks 1,2 , and 4 (visits 1,2 , and 3 ). At visit 0 (baseline), patients were given a diary to record the daily frequency of vomiting and diarrhea and the intensity of the other gastrointestinal symptoms over the first 2 weeks of the study.

The primary efficacy parameter was the presence of diarrhea in week 1 (assessed at visit 1). Secondary efficacy parameters were: the presence/absence of diarrhea in week 2 ; number of days without diarrhea in week 1 and week 2; presence/absence of other gastrointestinal symptoms (vomiting, taste disturbance, loss of appetite, nausea, epigastric pain, flatulence, constipation, skin rash) in weeks 1 and 2; patient-reported daily frequency of vomiting and diarrhea episodes in weeks 1 and 2; patientreported daily intensity of taste disturbance, loss of appetite, nausea, epigastric pain, 
bloating, constipation, and skin rash in weeks 1 and 2 (assessed on a 4-point scale, in which $0=$ no symptoms, $1=$ mild, $2=$ moderate, and $3=$ severe symptoms); and patients' global assessment of tolerability after week 1 and 2 (scored on a 5-point scale, in which $1=$ no symptoms, $2=$ mild symptoms that did not interfere with daily activities, $3=$ moderate symptoms that interfered slightly with daily activities, $4=$ severe symptoms that interfered with daily activities but did not result in treatment discontinuation, and $5=$ severe symptoms that required treatment discontinuation).

Safety of the study drug was assessed by monitoring the AEs and the vital signs at each study visit.

\section{Sample Size}

We estimated that a sample size of 130 would provide $80 \%$ power (two-sided $\alpha=0.05$ ) to detect the difference in the incidence of diarrhea between the $B$. clausii group and the placebo group, assuming the same incidences of diarrhea as in a previous randomized, doubleblind trial (placebo 30.8\%, B. clausii 9.3\%, placebo vs. B. clausii odds ratio 4.341) [15].

\section{Statistical Analysis}

The primary efficacy analysis was conducted in the intent-to-treat (ITT) population, which comprised all randomized patients who received at least one dose of the study drug and for whom at least one post-baseline efficacy assessment was available. A supportive analysis of the primary endpoint was conducted in the per-protocol (PP) population, comprising all randomized patients who completed the study therapy without any major protocol violation and had valid efficacy data at visit 1 . Safety was assessed in all randomized patients who received at least one dose of the study drug (the safety population).

Dichotomous variables were analyzed by $\chi^{2}$ test and the relative risk (RR) and 95\% confidence intervals (CI) were calculated. The daily episodes of diarrhea and vomiting and the daily intensity of other symptoms were summarized as overall means. An analysis of variance for repeated measures was applied to the ranktransformed data. Treatment, time, and the interaction between treatment by time were included in the model. The difference between groups for global assessment of tolerability was evaluated in the ITT population using the Wilcoxon test. All the statistical analyses were performed using the SAS system, v.8.2. All tests were two-sided and a $p$ value of $<0.05$ was considered statistically significant.

\section{RESULTS}

\section{Patient Disposition and Characteristics}

Overall, 130 patients were randomized to receive $B$. clausii $(n=65)$ or placebo $(n=65)$. All patients assigned to the $B$. clausii group completed the study, while one patient in the placebo group discontinued because of an $\mathrm{AE}$ (intestinal infection) 8 days after treatment initiation. Patient disposition is shown in Fig. 1. Patient demographic characteristics were well balanced between the treatment groups (Table 1).

\section{Primary Efficacy Outcome}

In the ITT population, the incidence of diarrhea at week 1 was significantly lower in patients receiving $B$. clausii than those receiving placebo ( $29 \%$ vs. $48 \%, p=0.03$ ), corresponding to a $39 \%$ reduction in the risk of diarrhea with $B$. clausii (RR 0.61; 95\% CI 0.39-0.97; Table 2). Results in the PP population supported the primary efficacy analysis, with a $39 \%$ reduction in the risk of diarrhea in patients receiving $B$. clausii than in those receiving placebo ( $p=0.0381$; Table 2).

\section{Secondary Efficacy Outcomes}

The risk of diarrhea remained significantly lower with $B$. clausii than with placebo at week 2, both in the ITT (RR 0.38; 95\% CI 0.14-1.02; $p=0.0422$ ) and PP populations (RR 95\% CI $0.25 ; \quad 0.07-0.84 ; \quad p=0.0130 ;$ Table 2). No 


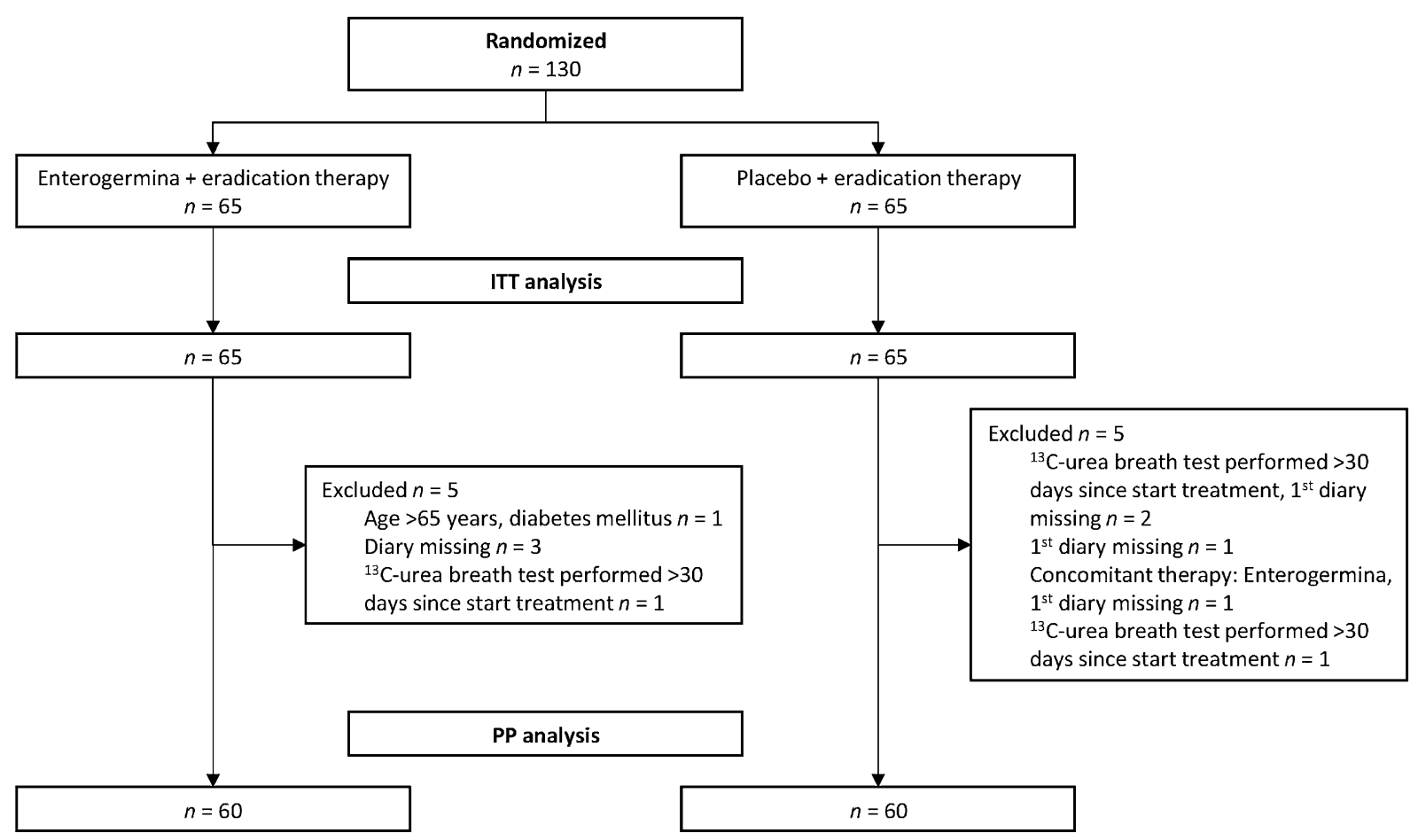

Fig. 1 Patient disposition

Table 1 Demographic characteristics (ITT population)

\begin{tabular}{|c|c|c|}
\hline Demographic data & $\begin{array}{l}\text { Bacillus clausii } \\
n=65\end{array}$ & $n=65$ \\
\hline Male $^{\mathrm{a}}, n(\%)$ & $28(43.08)$ & $26(40.00)$ \\
\hline Female $^{\mathrm{a}}, n(\%)$ & $37(56.92)$ & $39(60.00)$ \\
\hline $\begin{array}{l}\text { Age }^{\mathrm{b}}, \text { years } \\
\quad(\text { mean } \pm \mathrm{SD})\end{array}$ & $44.23(13.48)$ & $\begin{array}{l}42.38 \\
\quad(13.02)\end{array}$ \\
\hline \multicolumn{3}{|l|}{$\operatorname{Race}^{\mathrm{c}}, n(\%)$} \\
\hline Caucasian & $62(95.38)$ & $62(95.38)$ \\
\hline Black & $1(1.54)$ & $0(0.00)$ \\
\hline Oriental & $0(0.00)$ & $1(1.54)$ \\
\hline Other & $2(3.08)$ & $2(3.08)$ \\
\hline
\end{tabular}

ITT intent-to-treat, $S D$ standard deviation

${ }^{\mathrm{a}} p=0.7229$

b $p=0.4286$

c $p=0.5756$

significant difference between treatment groups was observed in the incidence of the other gastrointestinal symptoms at week 1 (Table 2). At week 2, the incidence of epigastric pain was significantly lower with $B$. clausii than with placebo (RR 0.50; 95\% CI 0.25-0.98; $p=0.0374$; Table 2).

In the ITT population, patients receiving $B$. clausii had significantly ( $p=0.0304)$ more days without diarrhea in week 1 than patients receiving placebo (6.25 vs. 5.86; Table 3$)$. In both, the $B$. clausii and placebo groups, the number of days without diarrhea increased significantly $(p<0.0001)$ from week 1 to week 2 , according to a repeated measures analysis (Table 3). In a repeated measures analysis, no significant difference between groups was observed in the number of days without symptoms (Table 3) or the patient-reported overall mean frequency/intensity (Table 4) of vomiting, taste disturbance, loss of appetite, nausea, epigastric pain, flatulence, constipation, or skin rash. In both treatment groups, for the majority of symptoms, the number of symptom-free days increased significantly (Table 3), and patientreported frequency/intensity decreased significantly (Table 4) from week 1 to week 2 . A significant interaction between treatment and 
Table 2 Incidence of symptoms

\begin{tabular}{|c|c|c|c|c|c|c|c|}
\hline \multirow[t]{2}{*}{ Symptoms } & \multirow[t]{2}{*}{ Population } & \multicolumn{3}{|l|}{ Week 1} & \multicolumn{3}{|l|}{ Week 2} \\
\hline & & $\begin{array}{l}\text { Bacillus } \\
\text { clausii (\%) }\end{array}$ & $\begin{array}{l}\text { Placebo } \\
(\%)\end{array}$ & RR; 95\% CI & $\begin{array}{l}\text { Bacillus } \\
\text { clausii (\%) }\end{array}$ & $\begin{array}{l}\text { Placebo } \\
(\%)\end{array}$ & RR; 95\% CI \\
\hline \multicolumn{8}{|c|}{ Primary outcome } \\
\hline \multirow[t]{2}{*}{ Diarrhea } & ITT & 29.23 & 47.69 & $0.61 ; 0.39-0.97^{*}$ & 7.69 & 20.00 & $0.38 ; 0.14-1.02^{*}$ \\
\hline & $\mathrm{PP}$ & 28.33 & 46.67 & $0.61 ; 0.37-0.99^{*}$ & 5.00 & 20.00 & $0.25 ; 0.07-0.84^{*}$ \\
\hline \multicolumn{8}{|c|}{ Secondary outcomes } \\
\hline Vomiting & ITT & 6.15 & 3.08 & $2.00 ; 0.38-10.54^{\mathrm{a}}$ & 3.08 & 3.08 & $1.00 ; 0.14-6.89^{\mathrm{a}}$ \\
\hline $\begin{array}{l}\text { Taste } \\
\text { disturbance }\end{array}$ & ITT & 52.31 & 56.92 & $0.92 ; 0.67-1.26$ & 18.46 & 23.08 & $0.80 ; 0.41-1.57$ \\
\hline $\begin{array}{l}\text { Loss of } \\
\text { appetite }\end{array}$ & ITT & 24.62 & 20.00 & $1.23 ; 0.64-2.35$ & 6.15 & 10.77 & $0.57 ; 0.18-1.86$ \\
\hline Nausea & ITT & 35.38 & 27.69 & $1.28 ; 0.77-2.13$ & 15.38 & 16.92 & $0.91 ; 0.41-1.99$ \\
\hline $\begin{array}{l}\text { Epigastric } \\
\text { pain }\end{array}$ & ITT & 46.15 & 44.62 & $1.03 ; 0.71-1.51$ & 15.38 & 30.77 & $0.50 ; 0.25-0.98^{*}$ \\
\hline Flatulence & ITT & 41.54 & 41.54 & $1.00 ; 0.66-1.50$ & 16.92 & 29.23 & $0.58 ; 0.30-1.12$ \\
\hline Constipation & ITT & 27.69 & 26.15 & $1.06 ; 0.60-1.87$ & 21.54 & 23.08 & $0.93 ; 0.49-1.77$ \\
\hline Skin rash & ITT & 4.62 & 9.23 & $0.50 ; 0.13-1.91^{a}$ & 10.77 & 4.62 & $2.33 ; 0.63-8.63$ \\
\hline
\end{tabular}

$C I$ confidence interval, $I T T$ intent-to-treat population, $P P$ per-protocol population, $R R$ risk ratio $X^{2}$ test ${ }^{*} p<0.05$ vs. placebo

a Fischer exact test; $X^{2}$ test was not valid as counts of $<5$ were expected in $50 \%$ of the cells

time was observed for the intensity of skin rash ( $p=0.0077$; Table 4).

Patients' global assessment of tolerability did not differ significantly between the two treatment groups (Table 5).

\section{Safety Outcomes}

In the safety population $(n=130)$, the mean duration of exposure to treatment was 14.14 $[ \pm 0.46$ standard deviation (SD)] days in the $B$. clausii group and 14.09 ( $\pm 1.07 \mathrm{SD}$ ) days in the placebo group.

Overall, three AEs were reported in the study, occurring in two placebo recipients (gastrointestinal mycosis and gastroenteritis due to enteropathogenic E. coli; and mild aphthous stomatitis). The AEs were not serious and were not considered related to treatment. The patient who had gastrointestinal mycosis and gastroenteritis required treatment interruption and specific treatment for these AEs. There was no significant difference between the two groups in the incidence of AEs $(p=0.4961)$.

No serious AEs, deaths or other significant AEs were reported in the study.

\section{DISCUSSION}

In this randomized, double-blind, placebo-controlled study, patients receiving 7-day tripletherapy for $H$. pylori eradication had a significantly lower incidence of diarrhea if they also received probiotic supplementation with $B$. clausii than if they received placebo. This benefit was observed in week 1 and sustained in week 2. Patients receiving $B$. clausii also had significantly more days without diarrhea than 
Table 3 Number of days without symptoms (ITT population)

\begin{tabular}{|c|c|c|c|}
\hline \multirow[t]{2}{*}{ Symptoms } & \multicolumn{2}{|l|}{ Overall mean $\pm S D$} & \multirow[t]{2}{*}{$p$ value ${ }^{\mathrm{a}}$ (treatment; time; treatment $\times$ time interaction) } \\
\hline & Bacillus clausii $n=65$ & $n=65$ & \\
\hline \multicolumn{4}{|l|}{ Diarrhea } \\
\hline Week 1 & $6.25 \pm 1.67$ & $5.86 \pm 1.88$ & $0.0304 ;<0.0001 ; 0.9028$ \\
\hline Week 2 & $6.77 \pm 1.26$ & $6.31 \pm 1.85$ & \\
\hline \multicolumn{4}{|l|}{ Vomiting } \\
\hline Week 1 & $6.97 \pm 0.82$ & $7.03 \pm 0.39$ & $0.8369 ; 0.8070 ; 0.7993$ \\
\hline Week 2 & $7.03 \pm 0.35$ & $7.02 \pm 0.28$ & \\
\hline \multicolumn{4}{|c|}{ Taste disturbance } \\
\hline Week 1 & $4.71 \pm 2.93$ & $4.34 \pm 2.89$ & $0.1373 ;<0.0001 ; 0.9748$ \\
\hline Week 2 & $6.80 \pm 0.67$ & $6.16 \pm 2.03$ & \\
\hline \multicolumn{4}{|c|}{ Loss of appetite } \\
\hline Week 1 & $6.06 \pm 2.23$ & $6.23 \pm 1.90$ & $0.7756 ; 0.0004 ; 0.3541$ \\
\hline Week 2 & $6.88 \pm 0.65$ & $6.55 \pm 1.75$ & \\
\hline \multicolumn{4}{|c|}{ Nausea (intensity) } \\
\hline Week 1 & $5.70 \pm 2.39$ & $6.26 \pm 1.75$ & $0.6678 ;<0.0001 ; 0.1719$ \\
\hline Week 2 & $6.72 \pm 1.00$ & $6.73 \pm 0.88$ & \\
\hline \multicolumn{4}{|c|}{ Epigastric pain } \\
\hline Week 1 & $5.67 \pm 2.22$ & $5.55 \pm 2.28$ & $0.3505 ;<0.0001 ; 0.1828$ \\
\hline Week 2 & $6.38 \pm 1.73$ & $6.09 \pm 1.81$ & \\
\hline \multicolumn{4}{|l|}{ Flatulence } \\
\hline Week 1 & $5.50 \pm 2.39$ & $5.41 \pm 2.44$ & $0.4939 ;<0.0001 ; 0.1788$ \\
\hline Week 2 & $6.28 \pm 1.89$ & $5.77 \pm 2.48$ & \\
\hline \multicolumn{4}{|c|}{ Constipation } \\
\hline Week 1 & $6.31 \pm 1.76$ & $6.28 \pm 1.83$ & $0.8618 ; 0.3638 ; 0.6237$ \\
\hline Week 2 & $6.30 \pm 1.84$ & $6.16 \pm 2.05$ & \\
\hline \multicolumn{4}{|l|}{ Skin rash } \\
\hline Week 1 & $7.03 \pm 0.53$ & $6.82 \pm 1.09$ & $0.9508 ; 0.6420 ; 0.0627$ \\
\hline Week 2 & $6.66 \pm 1.37$ & $6.86 \pm 1.04$ & \\
\hline
\end{tabular}

$I T T$ intent-to-treat, $S D$ standard deviation

${ }^{a}$ Repeated Measures ANOVA ( $p$ value of $F$ test)

those receiving placebo. Except for a lower incidence of epigastric pain with $B$. clausii at week 2 , the incidence of other gastrointestinal symptoms did not differ significantly between the two treatment groups. The B. clausii capsule formulation was well tolerated with no 
Table 4 Overall mean of patient-assessed frequency/intensity of gastrointestinal symptoms (ITT population)

\begin{tabular}{|c|c|c|c|}
\hline \multirow[t]{2}{*}{ Symptoms } & \multicolumn{2}{|l|}{ Overall mean $\pm S D$} & \multirow[t]{2}{*}{$p$ value (treatment; time; treatment $\times$ time interaction) } \\
\hline & Bacillus clausii $n=65$ & $n=65$ & \\
\hline \multicolumn{4}{|c|}{ Diarrhea (frequency) } \\
\hline Week 1 & $0.22 \pm 0.46$ & $0.26 \pm 0.51$ & $0.0585 ;<0.0001 ; 0.7085$ \\
\hline Week 2 & $0.10 \pm 0.41$ & $0.14 \pm 0.37$ & \\
\hline \multicolumn{4}{|c|}{ Vomiting (frequency) } \\
\hline Week 1 & $0.03 \pm 0.17$ & $0.01 \pm 0.07$ & $0.4605 ; 0.4697 ; 0.9799$ \\
\hline Week 2 & $0.01 \pm 0.04$ & $0.00 \pm 0.02$ & \\
\hline \multicolumn{4}{|c|}{ Taste disturbance (intensity) } \\
\hline Week 1 & $0.56 \pm 0.78$ & $0.60 \pm 0.75$ & $0.3325 ;<0.0001 ; 0.8767$ \\
\hline Week 2 & $0.04 \pm 0.11$ & $0.21 \pm 0.57$ & \\
\hline \multicolumn{4}{|c|}{ Loss of appetite (intensity) } \\
\hline Week 1 & $0.17 \pm 0.38$ & $0.17 \pm 0.40$ & $0.9818 ;<0.0001 ; 0.2476$ \\
\hline Week 2 & $0.02 \pm 0.10$ & $0.10 \pm 0.36$ & \\
\hline \multicolumn{4}{|c|}{ Nausea (intensity) } \\
\hline Week 1 & $0.28 \pm 0.55$ & $0.16 \pm 0.37$ & $0.4693 ;<0.0001 ; 0.2055$ \\
\hline Week 2 & $0.05 \pm 0.16$ & $0.04 \pm 0.12$ & \\
\hline \multicolumn{4}{|c|}{ Epigastric pain (intensity) } \\
\hline Week 1 & $0.30 \pm 0.52$ & $0.30 \pm 0.53$ & $0.4410 ;<0.0001 ; 0.1008$ \\
\hline Week 2 & $0.12 \pm 0.33$ & $0.19 \pm 0.39$ & \\
\hline \multicolumn{4}{|c|}{ Flatulence (intensity) } \\
\hline Week 1 & $0.32 \pm 0.57$ & $0.35 \pm 0.60$ & $0.4311 ;<0.0001 ; 0.1128$ \\
\hline Week 2 & $0.13 \pm 0.39$ & $0.26 \pm 0.58$ & \\
\hline \multicolumn{4}{|c|}{ Constipation (intensity) } \\
\hline Week 1 & $0.17 \pm 0.46$ & $0.13 \pm 0.31$ & $0.8995 ; 0.1549 ; 0.6481$ \\
\hline Week 2 & $0.16 \pm 0.48$ & $0.17 \pm 0.45$ & \\
\hline \multicolumn{4}{|c|}{ Skin rash (intensity) } \\
\hline Week 1 & $0.01 \pm 0.04$ & $0.05 \pm 0.24$ & $0.7858 ; 0.7822 ; 0.0077$ \\
\hline Week 2 & $0.06 \pm 0.23$ & $0.04 \pm 0.26$ & \\
\hline
\end{tabular}

Frequency is the mean number of daily episodes $I T T$ intent-to-treat, $S D$ standard deviation

${ }^{a}$ Repeated Measures ANOVA ( $p$ value of $F$ test)

treatment-associated AEs reported in patients receiving the formulation.
A similar study by Nista and colleagues with a B. clausii vial formulation (containing a watery 
Table 5 Patients' global assessment of tolerability (ITT population)

\begin{tabular}{|c|c|c|}
\hline Global assessment & $\begin{array}{l}\text { Bacillus clausii } \\
n=65\end{array}$ & $n=65$ \\
\hline \multicolumn{3}{|l|}{ Week $1^{\mathrm{a}}, n(\%)$} \\
\hline No symptoms & $14(21.54)$ & $6(9.23)$ \\
\hline Mild symptoms not interfering with daily activities & $32(49.23)$ & $\begin{array}{l}49 \\
(75.38)\end{array}$ \\
\hline Moderate symptoms interfering slightly in daily activities & $15(23.08)$ & $7(10.77)$ \\
\hline $\begin{array}{l}\text { Severe symptoms, seriously interfering with daily activities but not requiring } \\
\text { discontinuation }\end{array}$ & $4(6.15)$ & $2(3.08)$ \\
\hline Severe symptoms requiring discontinuation & $0(0.00)$ & $1(1.54)$ \\
\hline \multicolumn{3}{|l|}{ Week $2^{\mathrm{b}}, n(\%)$} \\
\hline No symptoms & $35(53.85)$ & $\begin{array}{l}24 \\
(36.92)\end{array}$ \\
\hline Mild symptoms not interfering with daily activities & $26(40.00)$ & $\begin{array}{l}38 \\
(58.46)\end{array}$ \\
\hline Moderate symptoms interfering slightly in daily activities & $3(4.62)$ & $2(3.08)$ \\
\hline $\begin{array}{l}\text { Severe symptoms, seriously interfering with daily activities but not requiring } \\
\text { discontinuation }\end{array}$ & $1(1.54)$ & $0(0.00)$ \\
\hline Severe symptoms requiring discontinuation & $0(0.00)$ & $0(0.00)$ \\
\hline
\end{tabular}

ITT intent-to-treat

${ }^{a}$ Wilcoxon test $p=0.8531$ vs. placebo

${ }^{\mathrm{b}} p=0.1269$ for week 2

suspension of $2 \times 10^{9}$ spores) also showed a significant reduction in the incidence of diarrhea compared with placebo in patients receiving 7-day triple therapy for $H$. pylori eradication therapy [15]. In addition, the incidence of nausea at week 1 and week 2 , as well as the incidence of epigastric pain at week 1 , were significantly reduced with $B$. clausii vial formulation than with placebo [15]. Of note, although the studies were very similar in their design, treatment, and duration, the primary objective of the study by Nista and colleagues was to determine the effect of treatment on the incidence of symptoms (such as diarrhea, epigastric pain, etc.), as well as $H$. pylori eradication rates. The incidence of diarrhea in the control group in this study was greater than that in the study by Nista [15]. Our results might be considered high by the standards of clinical trials, but within the range of what is seen in clinical settings in this indication. Recent meta-analyses have demonstrated that probiotic supplementation during $H$. pylori eradication therapy reduces the incidence of gastrointestinal symptoms, and that diarrhea incidence during $H$. pylori eradication therapy varies significantly between trials and might be as high as 58\% [2, 18-21].

Healthy gut microbiota has been recognized as key to several aspects of overall health, with one of its major properties being competitive exclusion of pathogens [22, 23]. Antibiotic therapy can disrupt this competitive exclusion machinery by various mechanisms, such as 
reducing the diversity and abundance of gut microbiota, resulting in overgrowth of pathogenic bacteria (e.g., diarrhea-causing bacteria) $[23,24]$. Probiotics help to restore the normal flora of the gut, thereby reducing AEs associated with the use of antibiotics [25]. Additionally, probiotics may have a beneficial effect on $H$. pylori eradication $[1,18,25]$. However, our study did not assess the eradication of $H$. pylori, as this was not one of its objectives. In the previous study with $B$. clausii vial formulation, the $H$. pylori eradication rate was similar between $B$. clausii and placebo groups. The $H$. pylori eradication rate in this study is expected to be similar as the capsule and vial formulations are bioequivalent [16]; however, this remains to be confirmed. The fact that this study was performed in a single country (Italy) could be considered a limitation. Since the intestinal microbiota of a patient varies geographically [26], and our study was performed in a single country, the effects observed with treatment are likely to vary depending on the geographic location and diet of other patients.

It should be noted that this study was conducted in 2003-2004 and used PPI-clarithromycin-containing triple therapy for $H$. pylori eradication. The effects of PPIs on gastrointestinal microbiota have been the subject of recent research interest [27]. By increasing gastric $\mathrm{pH}$, PPIs appear to promote the colonization of the gastrointestinal tract by orallyderived bacteria, particularly Streptococcus species [27]. An increase in the relative abundance of Streptococcus was observed in patients receiving PPIs regardless of their $H$. pylori infection status [28]. PPIs are some of the most widely used medications, and whether the use of $B$. clausii probiotics can ameliorate their effects on gastrointestinal microbiota is a promising future research area. Currently, however, triple therapy is not recommended for use in regions of the world where clarithromycin resistance is $>15 \%$, and additional studies are needed to assess the efficacy of the $B$. clausii capsule and vial formulations with bismuth quadruple or non-bismuth quadruple therapies [1].

\section{CONCLUSION}

In conclusion, this study shows that probiotic supplementation with $B$. clausii capsule formulation during 7-day triple-therapy for $H$. pylori eradication was well tolerated and effective in reducing the incidence of, and the number of days with, diarrhea relative to supplementation with placebo.

\section{ACKNOWLEDGMENTS}

We would like to thank the primary investigator for this study, Prof. Antonio Gasbarrini, Department of Internal Medicine, Gastroenterology Division, Policlinico "A. Gemelli" Hospital, Rome, Italy, and his staff. We would also like to thank the study participants.

Funding. The study and the Rapid Service Fee were funded by Sanofi.

Medical Writing and/or Editorial Assistance. We would like to thank Sohita Dillon, on behalf of Springer Healthcare Communications, and Georgii Filatov, of Springer Healthcare Communications, for providing medial writing assistance in accordance with Good Publications Practice (GPP3) guidelines (https:// www.ismpp.org/gpp3). This medical writing assistance was funded by Sanofi-Aventis.

Authorship. All named authors meet the International Committee of Medical Journal Editors (ICMJE) criteria for authorship for this article, take responsibility for the integrity of the work as a whole, and have given their approval for this version to be published.

Authorship Contributions. MP participated in the analysis of the data and contributed to drafting of the manuscript and revising each draft for important intellectual content. MP III and DG contributed to the analysis of the data and critically revised the drafts for important intellectual content. 
Disclosures. Manuel Plomer, Marcos Perez III and Dorothea Maren Greifenberg are employees of Sanofi-Aventis.

Compliance with Ethics Guidelines. All patients were required to sign a written informed consent form before participating in the clinical trial. The protocol, patient information sheet, and all the other study-related documents were submitted for approval to the institution's Independent Ethics Committee (IEC, Comitato Etico, Università Cattolica del Sacro Cuore, Policlinico A. Gemelli, Largo Gemelli, 8, 00168 Roma). Following local regulations, the IEC of the Centre released the "Giudizio di Notorietà" on April 23rd 2003, i.e. the permission to study Enterogermina in capsules formulation. On the same date the IEC approved the study protocol and the related study documentation. The study was performed according to the Helsinki declaration and in compliance with the International Council for Harmonisation of Technical Requirements for Registration of Pharmaceuticals for Human Use Good Clinical Practice guidelines adopted by the European Medicines Agency. This trial was conducted between June 2003 and May 2004, before the European database for clinical trials (EudraCT) was established, and is therefore not registered in a clinical study database.

Data Availability. Qualified researchers may request access to patient level data and related study documents including the clinical study report, study protocol with any amendments, blank case report form, statistical analysis plan and dataset specifications. Patient level data will be anonymized, and study documents will be redacted to protect the privacy of trial participants. Further details on Sanofi's data sharing criteria, eligible studies and process for requesting access can be found at https://www. clinicalstudydatarequest.com.

Open Access. This article is licensed under a Creative Commons Attribution-NonCommercial 4.0 International License, which permits any non-commercial use, sharing, adaptation, distribution and reproduction in any medium or format, as long as you give appropriate credit to the original author(s) and the source, provide a link to the Creative Commons licence, and indicate if changes were made. The images or other third party material in this article are included in the article's Creative Commons licence, unless indicated otherwise in a credit line to the material. If material is not included in the article's Creative Commons licence and your intended use is not permitted by statutory regulation or exceeds the permitted use, you will need to obtain permission directly from the copyright holder. To view a copy of this licence, visit http://creativecommons.org/licenses/by$\mathrm{nc} / 4.0 /$.

\section{REFERENCES}

1. Malfertheiner P, Megraud F, O'Morain CA, et al. Management of Helicobacter pylori infection-the Maastricht V/Florence Consensus Report. Gut. 2017;66:6-30.

2. Zhang M, Zhang C, Zhao J, et al. Meta-analysis of the efficacy of probiotic-supplemented therapy on the eradication of $H$. pylori and incidence of therapy-associated side effects. Microb Pathog. 2020: 104403 (Online ahead of print).

3. Bhalodi AA, van Engelen TSR, Virk HS, et al. Impact of antimicrobial therapy on the gut microbiome. J Antimicrob Chemother. 2019;74:i6-i15.

4. Graham DY, Fischbach L. Helicobacter pylori treatment in the era of increasing antibiotic resistance. Gut. 2010;59:1143-53.

5. Homan M, Orel R. Are probiotics useful in Helicobacter pylori eradication? World J Gastroenterol. 2015;21:10644-53.

6. Joint FAO/WHO Working Group. Guidelines for the evaluation of probiotics in food. 2002.

7. Jager R, Mohr AE, Carpenter KC, et al. International Society of Sports Nutrition position stand: probiotics. J Int Soc Sports Nutr. 2019;16:62.

8. Plaza-Diaz J, Ruiz-Ojeda FJ, Gil-Campos $\mathrm{M}$, et al. Mechanisms of action of probiotics. Adv Nutr. 2019;10:S49-S66.

9. Pique N, Berlanga M, Minana-Galbis D. Health benefits of heat-killed (tyndallized) probiotics: an overview. Int J Mol Sci. 2019;20:2534. 
10. Bermudez-Brito M, Plaza-Diaz J, Munoz-Quezada S, et al. Probiotic mechanisms of action. Ann Nutr Metab. 2012;61:160-74.

11. Markowiak P, Slizewska K. Effects of probiotics, prebiotics, and synbiotics on human health. Nutrients. 2017;9.

12. Rondanelli M, Faliva MA, Perna $S$, et al. Using probiotics in clinical practice: where are we now? A review of existing meta-analyses. Gut Microbes. 2017;8:521-43.

13. Liu Y, Tran DQ, Rhoads JM. Probiotics in disease prevention and treatment. J Clin Pharmacol. 2018;58(Suppl 10):S164-S179179.

14. Jezewska-Frackowiak J, Seroczynska K, Banaszczyk J, et al. The promises and risks of probiotic Bacillus species. Acta Biochim Pol. 2018;65:509-19.

15. Nista EC, Candelli M, Cremonini F, et al. Bacillus clausii therapy to reduce side-effects of anti-Helicobacter pylori treatment: randomized, double-blind, placebo controlled trial. Aliment Pharmacol Ther. 2004;20:1181-8.

16. Ghelardi E, Celandroni F, Salvetti S, et al. Survival and persistence of Bacillus clausii in the human gastrointestinal tract following oral administration as spore-based probiotic formulation. J Appl Microbiol. 2015;119:552-9.

17. European Medicines Agency (EMA): List of nationally authorised medicinal products. https://www. ema.europa.eu/en/medicines/ema_group_types/ ema_document-psusa?search_api_views_fulltext= b+clausii (2017). Accessed 26 May 2020.

18. Shi X, Zhang J, Mo L, et al. Efficacy and safety of probiotics in eradicating Helicobacter pylori: a network meta-analysis. Medicine (Baltimore). 2019;98: e15180.
19. Lu M, Yu S, Deng J, et al. Efficacy of probiotic supplementation therapy for Helicobacter pylori eradication: a meta-analysis of randomized controlled trials. PLoS ONE. 2016;11:e0163743.

20. Zhang MM, Qian W, Qin YY, et al. Probiotics in Helicobacter pylori eradication therapy: a systematic review and meta-analysis. World J Gastroenterol. $2015 ; 21: 4345-57$.

21. Ojetti V, Bruno G, Ainora ME, et al. Impact of Lactobacillus reuteri supplementation on anti-Helicobacter pylori levofloxacin-based second-line therapy. Gastroenterol Res Pract. 2012;2012:740381.

22. Valdes AM, Walter J, Segal E, et al. Role of the gut microbiota in nutrition and health. BMJ. 2018;361: k2179.

23. Jandhyala SM, Talukdar R, Subramanyam C, et al. Role of the normal gut microbiota. World J Gastroenterol. 2015;21:8787-803.

24. Barbut F, Meynard JL. Managing antibiotic associated diarrhoea. BMJ. 2002;324:1345-6.

25. Ji J, Yang H. Using probiotics as supplementation for Helicobacter pylori antibiotic therapy. Int J Mol Sci. 2020;21.

26. Lagier JC, Million M, Hugon $P$, et al. Human gut microbiota: repertoire and variations. Front Cell Infect Microbiol. 2012;2:136.

27. Minalyan A, Gabrielyan L, Scott D, et al. The gastric and intestinal microbiome: role of proton pump inhibitors. Curr Gastroenterol Rep. 2017;19:42.

28. Paroni Sterbini F, Palladini A, Masucci L, et al. Effects of proton pump inhibitors on the gastric mucosa-associated microbiota in dyspeptic patients. Appl Environ Microbiol. 2016;82:6633-44. 